\title{
Can community care workers deliver a falls prevention exercise program? A feasibility study
}

This article was published in the following Dove Press journal:

Clinical Interventions in Aging

\section{Elissa Burton' \\ Gill Lewin ${ }^{2}$ \\ Hilary O'Connell ${ }^{3}$ \\ Mark Petrich ${ }^{4,5}$ \\ Eileen Boyle' \\ Keith D Hill'}

'School of Physiotherapy and Exercise Science, Faculty of Health Sciences, Curtin University, Perth, Western Australia, Australia; ${ }^{2} \mathrm{School}$ of Nursing, Midwifery and Paramedicine, Faculty of Health Sciences, Curtin University, Perth, Western Australia, Australia; ${ }^{3}$ Independent Living Centre Western Australia, Perth, Western Australia, Australia; ${ }^{4}$ Western Australian Department of Health, Perth, Western Australia, Australia; ${ }^{5}$ School of Public Health, Faculty of Health Sciences, Curtin University, Perth, Western Australia, Australia
Correspondence: Elissa Burton School of Physiotherapy and Exercise Science, Curtin University, GPO Box U 1987, Perth, Western Australia 6845, Australia

Tel +6I 892664926

Fax +6I 892663699

Email e.burton@curtin.edu.au
Background: Almost half of older people receiving community care fall each year and this rate has not improved in the last decade. Falls prevention programs targeted at this group are uncommon, and expensively delivered by university trained allied health professionals.

Purpose: To investigate the feasibility of community care workers delivering a falls prevention exercise program to older clients, at low or medium risk of falling, as part of an existing service provision.

Patients and methods: Community care workers from 10 community care organizations participated in the training for, and delivery to their clients of, an 8-week evidence-based falls prevention exercise program. Community care workers included assessment staff (responsible for identifying the need for community care services through completing an assessment) and support workers (responsible for providing support in the home). Clients were surveyed anonymously at the completion of the intervention and workers participated in a semi-structured interview.

Results: Twenty-five community care workers participated in the study. The falls prevention program was delivered to 29 clients, with an average age of 82.7 (SD: 8.72) years and consisting of $65.5 \%$ female. The intervention was delivered safely with no adverse events recorded, and the eligibility and assessment tools were completed by the majority of community care workers (93.1\%). Assessment staff found it difficult to find time to deliver the intervention. Support workers were able to complete the intervention within their current service delivery period, with the initial assessment taking a small amount of additional time. Support workers reported enjoying the additional responsibility afforded by delivering the falls prevention program and seeing changes in their clients. The majority of clients (82\%) reported enjoying the exercises, with $59 \%$ reporting that they felt it made a positive change in their health. Clients completed the exercises on average 4.8 (SD: 2.2) days per week.

Conclusion: Community care workers who have completed appropriate training are able to deliver a falls prevention exercise program to their clients as part of their current services. Further research is required to determine whether the program reduces the rate of falls for community care clients and whether integration of a falls prevention program into an existing service is cost-effective.

Keywords: strength, balance, pragmatic research, home and community care services, Regional Assessment Service (RAS), safety

\section{Introduction}

Older people receiving community care services in Australia are twice as likely to fall as older people of the same age who are not receiving services, and these falls rates have not changed over the last decade. ${ }^{1-3}$ A million people aged 65 years and over living in Australia receive community care services every year due to experiencing physical or mental difficulties. ${ }^{4}$ Yet, the number of community care clients participating in falls prevention programs has decreased over the past 10 years. $^{2}$ 
Falls cost millions of dollars each year, ${ }^{5,6}$ which, combined with their association with hospital and residential care admission, provides substantial economic and social incentives for the governments to promote falls prevention programs targeting community care clients. Governmentsubsidized community care aims to help older people maximize their independence and avoid premature admission into residential care, ${ }^{7}$ and preventing the physical (eg, injuries) and mental (eg, lack of confidence and increased fear) consequences for older people can be devastating, and many do not recover to their former health status. ${ }^{8}$

Given that community care clients have a high falls rate and are likely to have increased care needs following a fall, but are not commonly accessing available falls prevention programs, it is suggested that such programs be incorporated into the community care services already being received. This may not only benefit the individual, but there may also be cost savings for both the health and aged care systems. When the community care clients participated in a falls prevention program, there was a $47 \%$ reduced likelihood of them subsequently falling, compared to those not receiving a falls prevention program. ${ }^{2}$

Community care is most commonly required because the older person is experiencing functional issues and finding daily activities such as showering, cleaning and shopping difficult. Services can include domestic assistance, personal care, transport, social services and gardening. These services are predominantly delivered by community care support workers, who often have vocational-level training to work together with the client on these activities. Depending on the needs of the older person, services may vary between occasional and daily on an ongoing basis. In some cases, support workers have more contact with their clients than the client's family.

Exercise interventions that incorporate balance and strength exercises have been shown to reduce falls in community-dwelling older people. ${ }^{9,10}$ Until relatively recently, there has been limited access to exercise programs within government-funded Australian community care. However, over the past 10-15 years, short-term restorative or reablement services delivered by allied health professionals have been introduced, which, for some clients, incorporate exercise programs. ${ }^{11-14}$ The studies examining the effectiveness of these services have not reported on pre- and postfall rates, although they have been found to be effective in increasing the strength and balance. ${ }^{11}$

Allied health professionals are not common among the staff of Australian community care organizations and their employment costs are substantially more than those of support workers. A recently published American study explored the ability of home care aides (may be considered equivalent to support workers in Australia) to increase the physical activity levels of frail older people accessing community care services through the use of chair-based activities and motivational techniques and found them to be effective. ${ }^{15}$

Given the existing evidence, it was hypothesized that the incorporation of a non-allied health (community care assessor and/or community care support worker) led falls prevention exercise program into the community care services received by frail older Australians would lead to a reduction in the likelihood of clients falling and needing an increase in services as a consequence. However, prior to evaluating this hypothesis in a large randomized trial, it was necessary to determine the feasibility and safety of this approach. The aim of this study was to examine whether an evidence-based falls prevention exercise program was feasible to be delivered safely by community care workers, working in 10 different community care organizations, as part of usual assessment and community care services.

\section{Patients and methods Design}

This was a feasibility study to determine whether community care support workers (ie, Regional Assessment Service [RAS] assessors and support workers) could deliver a falls prevention program (evidence-based strength and balance exercise program) within their usual service provision.

\section{Participants and setting}

Ten community care organizations across the Perth metropolitan area participated, nominating a minimum of two community care workers to attend the training and then deliver the program to a limited number of clients each. The inclusion criteria for community care workers participating were employed by one of the participating organizations and being able to complete the strength and balance exercises in order to demonstrate them to their clients. Community care workers included RAS assessors responsible for assessing individuals' need for services and support workers who delivered services such as personal care, domestic assistance, day centers and social care. While RAS assessors assess older people when they are first referred or their need is reviewed for community care, this process may take more than one visit and provide the opportunity for intervention. Client inclusion criteria were: aged 65 years and over and receiving at least 
one community care service from a participating community care organization or a RAS assessment.

\section{Sample size}

The sample size for the study was set at a maximum of 30 community care workers delivering the intervention to 60 clients (1 worker: $2-3$ clients). This was deemed a sufficient number to assess the feasibility of delivering the intervention, determine the recruitment and dropout rates and the time required to deliver the intervention to inform a larger trial, evaluate the ease of using the tools and establish an initial likelihood of adverse events.

\section{Recruitment process}

Each of the 10 community care organizations advertised the research project internally and asked their staff if they would like to participate. One organization offered the opportunity to all staff members, whereas all other organizations specifically targeted community care workers who they considered could deliver the intervention within their workloads. When the participating workers had completed training (see below), they recruited clients who met the inclusion criteria. Clients did not have to be receiving regular services from the participating worker; they could receive the falls prevention exercise program as an additional service for the 8-week study duration.

\section{Staff training}

Staff completed a 4-hour training session delivered by the lead researcher and a falls prevention specialist physiotherapist. The training included background on falls prevalence rates and community care clients; the benefits of strength and balance training for falls prevention; safety and risks of delivering exercise to older people; philosophy and concepts underpinning the Lifestyle-integrated Functional Exercise (LiFE) program (the intervention); ${ }^{16,17}$ completing the LiFE assessment tool; principles of balance and strength training and documentation to be completed for each client and staff member as part of the research project (eg, consent forms, client survey). Each staff member received three client folders which included the required documentation (information sheet and consent form; data collection sheets - see below; copy of each exercise; calendar; and a client survey and reply-paid envelope). Staff were trained how to obtain written informed consent from clients after inviting them to participate in the study and working through the participant information sheet with them. Each staff received a staff folder with explanation of the exercises and data sheets to be completed to record the timing, the mode of communication and the exercises discussed during each session. Staff members also received a trainer's manual for the LiFE program. ${ }^{18}$ All community care workers who participated in the training had access to the lead researcher via phone or email to have any questions answered as they arose. The lead researcher also sent group emails fortnightly on progress of the project.

\section{Data collection}

Initial data collected on the participating community care workers included demographics, position and duration worked at organization, plus qualifications. As part of determining client eligibility, community care workers completed the validated Falls Risk for Older People in the Community (FROP-Com) ${ }^{19}$ screening tool for each client. Clients with a score of six or above were referred to a falls prevention specialist, and clients with a score of five and below were deemed eligible to participate as they were at low to medium risk of falling. Workers also completed the Physical Activity Readiness Questionnaire (PARQ) ${ }^{20}$ for each client, and if the client answered "yes" to any of the questions (ie, possible medication or health issues when exercising), a doctor's certificate supporting their participation was required. Client demographic data recorded by workers included sex, age, marital and living status, health conditions and number of falls in the past 12 months. Workers also completed the $\mathrm{LiFE}$ assessment tool for each client and a data sheet for each session that the LiFE program was delivered. ${ }^{21}$ The data sheets included the time, the mode of communication, the exercises demonstrated or discussed and other comments (eg, how the client was progressing, adverse effects). All workers were interviewed at the completion of the intervention and the interview schedule is given in Supplementary material.

Clients were asked to complete a calendar to show adherence to the LiFE exercises. For each day they completed the exercises, they were required to tick the calendar. At the end of the 8-week intervention, each client was asked to complete a survey regarding their opinion on participating in the program, which exercises they liked and disliked and whether they noticed any change in their health. A survey rather than an interview was used to minimize client burden. The survey was anonymous and clients were provided with a reply-paid envelope and asked to post the completed survey back to the researchers once they had completed it.

\section{Intervention}

The fall prevention program (intervention) delivered by the community care workers was the LiFE program. LiFE is 
an evidence-based falls prevention exercise program that has been trialed with older community dwelling people not receiving community care services ${ }^{22}$ and also older people receiving restorative care services and is delivered by allied health professionals and nurses. ${ }^{11,23} \mathrm{LiFE}$ is designed to reduce falls and improve strength and balance by incorporating exercise into everyday activities. ${ }^{16,22}$ It includes seven balance and six strength exercises to improve lower body strength and balance and reduce falls. After completing the LiFE assessment tool, workers discussed with the client how the exercises recommended could be incorporated into their daily routines. The clients were given hard copy descriptions, with diagrams, of the exercises to be completed and were encouraged to complete the exercises while undertaking usual daily activities, for example, tandem walk when close to the kitchen bench when waiting for the kettle to boil. After completing the LiFE assessment tool and prescribing the initial exercises, the community care workers followed up with their clients either during their usual services or on a fortnightly basis. It was recommended that the community care workers describe two strength and two balance exercises initially, including more exercises where possible over subsequent weeks. The intervention period was for 8 weeks, as this was considered sufficient time to determine the safety and feasibility of the program for the clients and community care workers.

\section{Data analysis}

All quantitative data collected were analyzed using the SPSS for Windows, Version 24 software (IBM Corp., Armonk, NY, USA). The data analyzed included recruitment, dropout and tool completion rates; results from the FROP-Com screen, PARQ and LiFE assessment tool; community care worker and client demographic data; and client post-participation survey results. Traditional pre- and posttest physical performance outcome data (eg, improved strength, balance) were not collected for this study because the aim was not at this time to assess program effectiveness, but first to determine whether it was feasible for the community care workers to deliver the LiFE program and to identify the parameters around this (eg, time taken to deliver LiFE, ability to complete documentation and deliver the intervention).

Community care worker interviews were audio recorded, transcribed verbatim and imported into NVivo11 (qualitative data analysis software for coding and analysis; QSR International). All transcripts were read in their entirety and subjected to thematic analysis. ${ }^{24}$ Two researchers undertook the initial coding independently $(\mathrm{EB}, \mathrm{EJB})$ to generate codes from relevant words, phrases and sentences. ${ }^{24}$ Codes with similar meaning were then grouped and collapsed to form themes and categories pertinent particularly to the challenges of delivering the intervention. The researchers then met, discussed any differences in their analyses and where necessary, returned to the data to resolve any variances. Trustworthiness was improved by including an experienced qualitative researcher (EB) to lead the analysis and a second researcher (EJB) who coded the data independently. ${ }^{25}$ Triangulation was achieved by validating the completed worker data sheets with the information provided during the interviews.

\section{Ethics approval}

Ethics approval (HRE2016-0324) was granted by Curtin University's Human Research Ethics Committee. All participants (staff and clients) were given a participant information sheet and were allowed time to ask questions about the research project, and they provided written informed consent prior to participating in the study.

\section{Results}

\section{Recruitment and dropout rates}

Twenty-five community care workers (6 RAS assessors, 19 support workers) across the 10 organizations completed the training and consented to participate in the study, involving recruiting clients and delivering the LiFE exercise program. Sixty percent of community care workers $(n=15)$ recruited at least one client (3 workers recruited one client, 10 workers recruited two clients and 2 workers recruited three clients). Three RAS assessors (50\%) and 12 support workers (63.2\%) recruited at least one client. Ninety-nine clients were asked if they would like to participate and 33 clients were recruited (recruitment rate: $33.3 \%$ ). Community care workers who recruited at least one client asked an average of four clients (range: 1-10). Nine community care workers $(36.0 \%)$ recruited no clients and these workers also asked an average of four clients each to participate (range: $0-11$ ). Two community care workers did not ask any clients to participate.

Twenty-nine clients (87.9\%) completed the intervention; four withdrew (12.1\%). Reasons for withdrawal included illness $(n=2)$, lack of interest $(n=1)$ and not being able to obtain doctor's certificate $(n=1)$.

\section{Client demographics}

The average age of the clients was 82.7 years (SD: 8.72 ) and $65.5 \%$ were female $(n=19)$. Fifty-nine percent $(n=17)$ were widowed, $34.5 \%$ were married/de facto $(n=10)$ and $3.4 \%$ were either separated or never married ( $n=1$, respectively). 
Over two-thirds of clients lived alone ( $\mathrm{n}=20), 24.1 \%$ lived with a partner $(n=7)$ and $6.9 \%$ lived with other family members ( $\mathrm{n}=2)$. Only $10.3 \%$ were current smokers $(n=3)$. Almost half of all clients $(48.3 \%, \mathrm{n}=14)$ reported a visual impairment, though all were able to read written exercise instructions with the use of their usual glasses; also, 37.9\% had a hearing impairment $(\mathrm{n}=11), 34.5 \%$ had osteoporosis $(\mathrm{n}=10), 24.1 \%$ had spinal issues ( $\mathrm{n}=7)$ and $20.7 \%$ had diabetes $(\mathrm{n}=6)$.

Forty-five percent of clients had fallen in the past 12 months $(n=13)$. Thirty-four percent of clients reported no trouble walking $(n=10), 6.9 \%$ noted trouble walking but did not use an aid $(\mathrm{n}=2), 27.6 \%$ used a walking aid outside $(n=8)$ and $31.0 \%$ used a walking aid inside $(n=9)$.

\section{Outcome measures}

The FROP-Com and the PARQ were completed fully for all clients, and 27 of the 29 (93.1\%) LiFE assessment tools were also fully completed ( 2 were partially completed). Eighty-six percent of the community care worker data sheets $(n=25)$ were fully completed.

Sixty-nine percent of the clients scored low risk on the FROP-Com screen (score $0-3 ; \mathrm{n}=20$ ), 27.6\% scored medium risk (score $4-5 ; n=8$ ) and $3.4 \%$ scored high risk (score 6-9; $\mathrm{n}=1$ ). The average FROP-Com screen score was 2.5 (SD: 1.9), with a range of $0-6$. After completing the PARQ tool, six clients went to their doctor and received approval to participate in the LiFE exercise program (20.7\%). All doctors who were approached encouraged patient participation. Results from the LiFE assessment tool are presented in Tables 1 and 2. For the balance and strength exercises (except moving sideways), the highest proportion of clients scored Level 0, which is either being unable to perform or using support. In general, clients had lower scores for the balance exercises than strength exercises.

\section{Intervention delivery}

A number of themes arose from the community care worker interviews. These included how they recruited clients, the positive experiences, the challenges of participating, suggestions also by the RAS assessors on how they could be utilized differently to how they were used in the current study and the type of exercises preferred by the clients.

\section{Community care worker interviews and reports about intervention delivery}

Six community care workers stated they selected specific clients to invite to participate, while some of the other participating support workers invited clients from outside their
Table I LiFE assessment tool ${ }^{18}$ - preliminary question results (sample $\mathrm{N}=29$ )

\begin{tabular}{|c|c|c|}
\hline Musculoskeletal history & $\mathbf{n}$ & $\%$ \\
\hline Arthritis in knees of hips (Yes) & 10 & 34.5 \\
\hline Joint replacements in your hips or knees (Yes) & 8 & 27.6 \\
\hline Ever had or get bursitis/tendinitis in leg/legs? (Yes) & I & 3.4 \\
\hline Get or had lower back pain (Yes) & 14 & 48.3 \\
\hline \multicolumn{3}{|l|}{ Functional balance questions } \\
\hline \multicolumn{3}{|l|}{ Do you sit or stand when dressing? } \\
\hline Sit & 5 & 17.2 \\
\hline Mostly sit & 8 & 27.6 \\
\hline Mostly stand & 11 & 37.8 \\
\hline Stand & 5 & 17.2 \\
\hline \multicolumn{3}{|l|}{ Do you sit or stand up to put on shoes and socks? } \\
\hline Sit & 25 & 86.2 \\
\hline Stand & 4 & 13.8 \\
\hline \multicolumn{3}{|l|}{ Do you sit down or stand up to put on your pants? } \\
\hline Sit & 19 & 65.5 \\
\hline Stand & 10 & 34.5 \\
\hline \multicolumn{3}{|l|}{ Do you sit or stand up to put on your bra or singlet? } \\
\hline Sit & 10 & 35.7 \\
\hline Stand & 18 & 64.3 \\
\hline \multicolumn{3}{|l|}{ Do you sit or stand up to shower? } \\
\hline Sit & 7 & 24. 1 \\
\hline Stand & 22 & 75.9 \\
\hline $\begin{array}{l}\text { During your shower, do you hold onto anything } \\
\text { for support? (Yes) }\end{array}$ & 16 & 55.2 \\
\hline \multicolumn{3}{|c|}{$\begin{array}{l}\text { How confident are you that you can get dressed without losing } \\
\text { your balance? }\end{array}$} \\
\hline Not at all confident & 5 & 17.9 \\
\hline A little confident & 3 & 10.7 \\
\hline Fairly confident & 15 & 53.6 \\
\hline Very confident & 5 & 17.8 \\
\hline Do you use a walking stick or frame? (Yes) & 16 & 55.2 \\
\hline \multicolumn{3}{|l|}{ If yes, when do you use it? } \\
\hline Always & 4 & 25 \\
\hline When going out & 7 & 43.7 \\
\hline Varies - use it as needed & 5 & 31.3 \\
\hline $\begin{array}{l}\text { Are you able to step down a curb/gutter without } \\
\text { assistance? (Yes) }\end{array}$ & 17 & 58.6 \\
\hline
\end{tabular}

Abbreviation: LiFE, Lifestyle-integrated Functional Exercise.

usual caseload due to their usual clients being considered to have too high needs:

We had a bit of difficulty with mine because a lot of mine were high level so I didn't even use any of my regular clients. We had to go to the other section of the company to find lower care clients. [worker \#5]

The RAS assessors who recruited clients only invited individuals they already knew and were due for a review of their service needs:

I kind of handpicked, so I went through my review list and thought now, who would be willing to do this for me. I also think a lot of that is in terms of how we have always run 
Table 2 LiFE assessment tool ${ }^{18}$ - balance and strength activity levels and percentage of sample commencing program at each level

\begin{tabular}{|c|c|c|c|c|c|}
\hline Balance activities, n (\%) & Level 0 & Level I & Level 2 & Level 3 & Level 4 \\
\hline Tandem stand & $10(35.7)$ & $10(35.7)$ & $3(10.7)$ & $5(17.9)$ & $0(0)$ \\
\hline Tandem walk & $12(42.9)$ & $8(28.6)$ & $6(21.4)$ & $2(7.1)$ & $0(0)$ \\
\hline One-leg stand & $13(44.8)$ & $8(27.6)$ & $3(10.3)$ & $3(10.3)$ & $2(6.9)$ \\
\hline Leaning forward and backward & $15(53.6)$ & $4(14.3)$ & $5(17.9)$ & $4(14.3)$ & $0(0)$ \\
\hline Forward and backward & $13(46.4)$ & $5(17.9)$ & $3(10.7)$ & $7(25.0)$ & $0(0)$ \\
\hline \multicolumn{6}{|l|}{ Strength activities, $\mathbf{n}(\%)$} \\
\hline Squatting & $13(48.1)$ & $5(18.5)$ & $9(33.3)$ & $0(0)$ & $0(0)$ \\
\hline Walking on toes & $10(37.0)$ & $7(25.9)$ & $4(14.8)$ & $2(7.4)$ & $4(14.8)$ \\
\hline Walking on heels & $10(34.5)$ & $4(14.8)$ & $6(22.2)$ & $2(7.4)$ & $5(18.5)$ \\
\hline Standing up from a seated position & $9(33.3)$ & $5(18.5)$ & $4(14.8)$ & $9(33.3)$ & $0(0)$ \\
\hline Move sideways & $6(22.2)$ & $6(22.2)$ & I5 (55.6) & $0(0)$ & $0(0)$ \\
\hline
\end{tabular}

Abbreviation: LiFE, Lifestyle-integrated Functional Exercise.

HACC [community care] in terms of they have never had to do anything like this before. It's always been I call up and get a service, where [for this] we are actually making them do some work. [worker \#9]

The RAS assessors suggested it would be difficult to recruit new clients or those who come back into the system due to illness or injury (ie, retrigger).

If I had to do it with news or re-triggers it probably would have been a lot harder for me. I really had to handpick who

I was going to try and do this with. [worker \#9]

Clients who participated in the exercise program were described as motivated, keen, determined and strong willed, for example:

I knew that two of them would be keen because they do try. [worker \#6]

and

He's proactive, he likes to exercise. [worker \#14]

All of the community care workers suggested they experienced positive aspects to delivering the falls prevention program. These included feeling good about the clients improving their health:

For me I found this whole experience has been very rewarding, as I have seen huge improvements, especially with one of my clients and because I got something out of it as well. I got to enjoy seeing her do these things and taking pride in doing them. That's a really nice feeling. [worker \#3]

Others enjoyed it because it was different to their usual services

I really enjoyed turning up there and just focusing on that instead of other services. and

I just - felt so proud, to do something like that, because it improves their life, and it's interesting. [worker \#5]

Seven support workers reported practicing the exercises before they went out to see their clients and found the exercises to be good for them also

I enjoyed it, yeah. It's really good. I actually do it at home.

[worker \#14]

The community care workers also described experiencing a number of challenges when delivering the intervention. Table 3 presents their descriptions of the types of challenges they experienced. These included clients only wanting to exercise when support workers were present, experiencing fear and thinking walking was enough to prevent falls. Participating community care workers also reported that some clients were only interested in receiving services such as domestic assistance or social care and were not interested in trying to improve their physical status or prevent future falls. The word "exercise" was also seen by support workers and RAS assessors as being perceived negatively by older clients when trying to encourage them to be more active.

The RAS assessors also reported that for them, finding sufficient time for the intervention was difficult. The reasons they gave for this included having client targets that they needed to meet and difficulties containing workloads:

We've got KPIs hanging over our heads. [worker \#4]

and

I think it would have been a breeze if we weren't busy, basically. [worker \#9]

Recruitment happened at a time for the RAS assessors when national changes to the aged care system were being 
Table 3 Challenges for workers when delivering the intervention

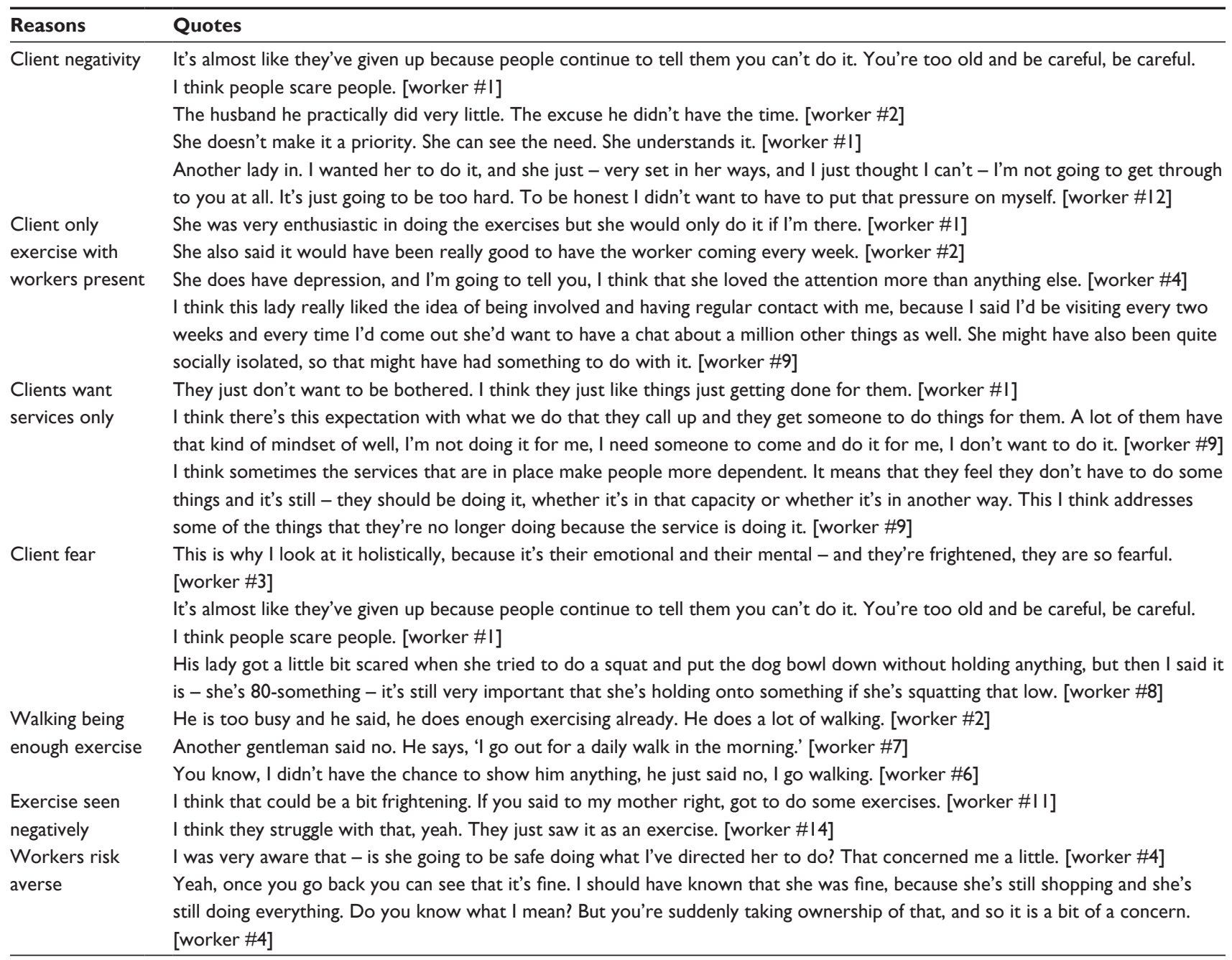

made, which resulted in an increase in the number of referrals to the RASs, putting pressure on assessors:

With the national waitlist, because it's taking so long for them to come through to move onto a package, we're like the in-between referral to tide them over until then. Which means that we've just got a huge amount of referrals. [worker \#9]

Two RAS assessors suggested it may work better if they could refer clients to community care organizations whose support workers have been trained to deliver LiFE:

It's the time factor. We don't have the luxury of doing that. I'd be happy to do it as part of an assessment, saying client would benefit from LiFE program, and direct a service provider to do that. [worker \#4]

and

If we got a referral for someone and we deem that they didn't need ongoing support and they're very low level, if we could refer to someone to say okay, I think you'd benefit from the LiFE program to prevent any falls or anything else, I think that would be good. I think us trying to do it would be difficult for new clients. [worker \#9]

Both the assessors and the support workers also reported that, in general, clients enjoyed the strength exercises more than the balance, with some clients being fearful of completing the balance exercises:

The three participants were pretty much scared to do the balancing exercises because it's probably the main factor why - or the main reason why they fall down. [worker \#2]

and

She was finding strength better than balance. [worker \#11]

Of all the exercises given to clients, and the full range of LiFE exercises were given to different clients; standing on 
heels and walking on heels were said to be the two that the clients had most difficultly completing.

\section{Time to deliver intervention}

When support workers delivered the exercise program as part of the services they were already providing to a client, the average service time recorded was 11.5 hours over the 8 weeks of the program. This was only a quarter of an hour longer than the average service time recorded for these clients over an 8 -week period 3 months prior to the project. However, the four support workers who delivered the exercise program to seven people who were not their regular clients took an average of 5 hours to complete the assessment and deliver LiFE over the 8 weeks. In comparison, the RAS assessors took an average of 3.5 hours to complete the assessments and deliver the intervention to their clients as part of the usual review process; whereas the usual length of an annual face-to-face review, including both assessment and write up, is 1.5-2 hours.

\section{Client adherence and satisfaction}

Based on their calendar entries, clients completed exercises an average of 4.8 (SD: 2.2) days per week. Twenty-two of the 25 clients returned the satisfaction survey $(88.0 \%)$. Eighty-two percent $(n=18)$ reported enjoying the exercises, three did not (13.6\%) and one was unsure (4.5\%). Almost two-thirds of clients $(59.1 \%, \mathrm{n}=13)$ reported finding at least one of the exercises difficult, while $31.8 \%$ said they did not find any exercises difficult to complete $(n=7)$. The exercises found to be the most difficult involved balance such as tandem stand and walk, one leg stand, forward-backward weight shift, standing or walking on toes, climbing steps or stepping over something. Fifty-nine percent of the clients noted feeling a positive change in their health since starting the exercise program $(n=13)$, while the other eight clients did not report any noticeable changes (36.4\%) and one showed decline in health, but they reported it was nothing to do with the LiFE program.

\section{Adverse events}

No serious adverse events were reported by the clients while completing the exercises. One client did experience muscle soreness during the first few weeks of doing the exercises, but persisted with the program and this settled.

\section{Discussion}

This feasibility study demonstrated it is possible for support workers delivering community care services and RAS assessors completing annual client reviews to deliver this falls prevention exercise program. The majority of clients reported enjoying being involved and two-thirds noted changes in their health, even though many found at least one exercise difficult. Support workers generally saw clients fortnightly, yet clients completed the exercises around four times a week, showing it was possible for this population to participate in a falls prevention exercise program without continual supervision. The study also showed that it is safe for the LiFE exercise program to be delivered by RAS assessors and support workers trained in the implementation of the program, as no adverse events were reported.

Client recruitment rates were low and the factors influencing recruitment of community care clients into this type of program need to be better understood. The low rate was, however, not unlike that experienced by other studies both in Australia ${ }^{11}$ and in other parts of the world ${ }^{26,27}$ which have tried to recruit community care clients to participate in an intervention. It appears that older people who require assistance to live independently in the community may decline opportunities to improve their function, and that they are wary when the word "exercise" is used. Muramatsu et al explored the feasibility of home care aides in USA for delivering a brief motivational enhancement and an exercise program (which included chair-bound exercises) to clients receiving Medicaid-funded services and reported that using the word "exercise" to describe the intervention appeared to put off their older home care clients. ${ }^{15}$ It is, therefore, suggested that when trying to recruit community care clients to falls prevention programs, staff avoid talking about an exercise program and instead focus on balance and movement improvement strategies or movement programs, as suggested by a support worker.

The FROP-Com, PARQ and LiFE assessment tools were all found to be suitable for community care workers to use, both in determining eligibility for a program of this nature and secondly as the basis for suggesting what exercises are going to be most helpful. The study also found that it was possible for the assessment to be completed and the program to be delivered as part of usual service provision by support workers without needing a substantial increase in the service time allocated. RAS assessors, on the other hand, struggled to find the time to deliver the program and the time they did find was in addition to the time needed to complete a "normal" review.

Australian governments adopted a wellness approach to community care provision as part of aged care reforms, in which clients are encouraged to participate in the services, build 
on their strengths and increase their capacity. However, many clients appear to still think community care is about someone doing things for them that they have difficulty doing by themselves. Unless community care is qualitatively different from a privately funded service provider, government subsidization is simply a resource redistribution. Policy settings will need to fully reflect the government's position on this issue.

Research has shown that older people, including those receiving community care services, prefer walking to all other forms of exercise/physical activity. ${ }^{28-31}$ Some of the individuals invited to participate in this study said they felt they were already sufficiently active as they walked regularly. Walking alone has not, however, been found to reduce the likelihood of falls and, in some cases, has actually been found to increase falls rates. ${ }^{32,33}$ Balance and strength programs, including the LiFE exercise program, ${ }^{16}$ on the other hand, have been shown to reduce the rate of falls. ${ }^{9,10}$ Hence, these exercises are important for community care clients who, as a population, have a high falls rate. In general, clients' balance was assessed by community care workers as poorer than their strength, but most clients preferred doing the strength rather than the balance exercises. Client adherence to the exercises was good at 4.8 days per week, which was consistent with previous research for community care clients receiving shortterm restorative care services that has reported it to be between 3.62 and 4.91 times per week. ${ }^{23}$ Ongoing encouragement by community care workers to complete regular balance exercises may be an important key to reducing the falls rate for this population. This needs to be examined in future research.

\section{Limitations}

This study was limited by the small numbers of both clients and community care workers involved. However, given that both community care workers and clients came from 10 different community care organizations, the results are more generalizable than if a larger sample from just one organization had been used. Some community care workers "selecting" the clients to participate could also be a limitation if this was to be delivered across community care services. However, further research is required to understand the effectiveness of the service and also how to encourage more clients to participate, in order to reduce the falls rate for this population.

\section{Conclusion}

This study indicates that it is feasible for trained community care workers to safely deliver a falls prevention exercise program as part of usual service provision without substantially increasing the service time required. Research is now required to determine whether delivery of such a program actually reduces the falls rate of the participating clients.

\section{Acknowledgments}

This research was funded by a Western Australian Home and Community Care Program grant. The authors would like to thank the community care organizations, staff and clients for their participation in the study.

\section{Disclosure}

MP is employed by the Western Australian Department of Health that manages the Western Australian Home and Community Care (HACC) Program. The other authors report no conflicts of interest in this work.

\section{References}

1. Burton E, Lewin G. Characteristics of older people who fall, cannot get up and call emergency services for help? J Am Geriatr Soc. 2016; 64(1):217-218.

2. Burton E, Lewin G, O'Connell H, Hill KD. Falls prevention in community care: ten years on. Clin Interv Aging. 2018;13:261-269.

3. Smith J, Lewin G. Home care clients' participation in fall prevention activities. Australas J Ageing. 2008;27(1):38-42.

4. Aged Care Research \& Evaluation Unit. Home and Community Care (HACC) Program: Minimum Data Set Report 2013-2014. Annual Report. Perth, WA: Government of Western Australia, Department of Health; 2014.

5. Hendrie D, Miller T, Randall S, Brameld K, Moorin R. Incidence and Costs of Injury in Western Australia 2012. Perth, WA: Department of Health - Chronic Disease Prevention Directorate; 2016.

6. Watson W, Clapperton A, Mitchell R. The Incidence and Cost of Falls Injury Among Older People in New South Wales 2006/07. Sydney: NSW Department of Health; 2010.

7. Government of Western Australia. HACC - Home and Community Care Program. Available from: http://ww2.health.wa.gov.au/Articles/F_I/ HACC-Home-and-Community-Care-Program. Accessed October 17, 2017.

8. AIHW: Pointer S. Trends in Hospitalised Injury, Australia 1990-00 to 2012-13. Injury Research and Statistics Series No. 95. Cat. No. INJCAT 171. Canberra: AIHW; 2015.

9. Gillespie LD, Robertson MC, Gillespie WJ, et al. Interventions for preventing falls in older people living in the community. Cochrane Database Syst Rev. 2012;(9).

10. Sherrington C, Michaleff Z, Fairhall N, et al. Exercise to prevent falls in older adults: an updated systematic review and meta-analysis. $\mathrm{Br} J$ Sports Med. 2017;51(24):1750-1758.

11. Burton E, Lewin G, Clemson L, Boldy D. Effectiveness of a lifestyle exercise program for older people receiving a restorative home care service: a pragmatic randomized controlled trial. Clin Interv Aging. 2013;8:1591-1601.

12. Lewin G, Calver J, McCormack B, et al. The home independence project. Geriaction. 2008;26(3):13-20.

13. Lewin G, De San Miguel K, Knuiman M, et al. A randomised controlled trial of the Home Independence Program, an Australian restorative homecare programme for older adults. Health Soc Care Community. 2013; 21(1):69-78.

14. Lewin G, Vandermeulen S. A non-randomised controlled trial of the Home Independence Program (HIP): an Australian restorative programme for older home-care clients. Health Soc Care Community. 2010; 18(1):91-99. 
15. Muramatsu N, Yin L, Berbaum ML, et al. Promoting seniors' health with Home Care Aides: a pilot. Gerontologist. Epub 2017 Jun 17.

16. Clemson L, Singh M, Bundy A, et al. LiFE Pilot Study: a randomised trial of balance and strength training embedded in daily life activity to reduce falls in older adults. Aust Occup Ther J. 2010;57(1):42-50.

17. Clemson L, Singh M, Cumming B, Weissel E, Manollaras K. LiFE: Lifestyle Approach to Reducing Falls Through Exercise. Sydney, NSW: The University of Sydney; 2007.

18. Clemson L, Munro J, Fiatarone Singh M. Lifestyle-integrated Functional Exercise (LiFE) Program to Prevent Falls: Trainers Manual. Sydney, NSW: Sydney University Press; 2014.

19. Russell MA, Hill KD, Day LM, Blackberry I, Gurrin LC, Dharmage SC. Development of the Falls Risk for Older People in the Community (FROP-Com) screening tool. Age Ageing. 2009;38(1):40-46.

20. Chisholm D, Collis M, Kulak L, et al. PAR-Q Validation Report: the Evaluation of a Self-Administered Pre-exercise Screening Questionnaire for Adults. Victoria, BC: BC Ministry of Health and Health and Welfare Canada; 1978.

21. Friery L. Rasch Analysis of the LiFE Assessment and Functional Balance and Strength. Lidcombe, NSW, The University of Sydney; 2007.

22. Clemson L, Fiatarone Singh MA, Bundy A, et al. Integration of balance and strength training into daily life activity to reduce rate of falls in older people (the LiFE study): randomised parallel trial. BMJ. 2012; $345: \mathrm{e} 4547$.

23. Burton E, Lewin G, Clemson L, Boldy D. Long term benefits of a lifestyle exercise program for older people receiving a restorative home care service: a pragmatic randomized controlled trial. Healthy Aging Clin Care Elder. 2014;6:1-9.

24. Braun V, Clarke V. Using thematic analysis in psychology. Qual Res Psychol. 2006;3(2):77-101.
25. Lincoln Y, Guba E. Naturalistic Enquiry. Newbury Park, CA, USA: Sage Publications; 1985.

26. Markle-Reid M, Weir R, Browne G, Roberts J, Gafni A, Henderson S. Health promotion for frail older home care clients. J Adv Nurs. 2006; 54(3):381-395.

27. McMurdo ME, Roberts H, Parker S, et al; Age and Ageing Specialty Group, NIHR, Comprehensive Clinical Research Network. Improving recruitment of older people to research through good practice. Age Ageing. 2011;40(6):659-665.

28. Burton E, Lewin G, Boldy D. Physical activity levels of older people receiving a home care service. J Aging Phys Act. 2013;21(2): 140-154.

29. Burton E, Lewin G, Boldy D. Physical activity preferences of older home care clients. Int J Older People Nurs. 2015;10(3):170-178.

30. Saarloos D, Nathan A, Almeida O, Giles-Corti B. The Baby Boomers and Beyond Report: Physical Activity Levels of Older Western Australians 2006. Perth: Western Australia: Western Australian Government; 2008.

31. Szanton SL, Walker RK, Roberts L, et al. Older adults' favorite activities are resoundingly active: findings from the NHATS study. Geriatr Nurs. 2015;36(2):131-135.

32. Ebrahim S, Thompson PW, Baskaran V, Evans K. Randomized placebocontrolled trial of brisk walking in the prevention of postmenopausal osteoporosis. Age Ageing. 1997;26(4):253-260.

33. Voukelatos A, Merom D, Sherrington C, Rissel C, Cumming RG, Lord SR. The impact of a home-based walking programme on falls in older people: the easy steps randomised controlled trial. Age Ageing. 2015;44(3):377-383. 


\section{Supplementary materials \\ Community care workers - final interview questions for those who recruited clients}

Can you please tell me about your involvement in the research project?

How many clients do you currently assist on your roster?

Did you recruit any clients into the Lifestyle-integrated Functional Exercise (LiFE) exercise program? If yes carry on

How many clients did you ask or assess before you recruited your clients?

Did you need to check with the doctor before your clients began?

If yes, how many clients did you check with the doctor?

Was this part of the process difficult for you or the client?

Would you suggest any changes to this process?

How did you find using the Falls Risk for Older People in the Community (FROP-Com) screening tool to determine falls risk for your clients?

Do you think clients assessed as low to medium risk on the FROP-Com are appropriate for being given the LiFE exercise program?

How did you find using the Physical Activity Readiness Questionnaire (PARQ) tool to determine eligibility for your clients?

How did you find conducting the LiFE assessment tool and grading your clients?

How did you find delivering the LiFE exercise program with your clients?

How do you think your clients found participating in the LiFE exercise program?

Do you think your clients gained any benefit from the LiFE program?
Did any of your clients both inside the LiFE project and your other clients have a fall since you were doing the LiFE program?

Did you enjoy delivering an exercise program to your clients?

Did you enjoy being involved in the research project?

Thank you for taking part in the research project. Are there any aspects you think we need to change to help community care workers or community care clients in the future?

\section{Community care workers - final} interview questions - those who did not recruit clients

How many clients do you currently assist on your roster?

Did you recruit any clients into the LiFE exercise program? If No carry on

Why do you think that was?

Can you tell me a little more about why you think they weren't suitable?

What do you think were the main reasons why you were unable to recruit any clients?

After completing the training how did you feel about the prospect of delivering the LiFE exercise program to two of your clients?

Have any of your clients experienced a fall previously? Were they given any advice to try and reduce the chance of falling in the future?

Who do you think the LiFE program might be most suited to?

Did you enjoy being involved in the research project?

Thank you for taking part in the research project. Are there any aspects you think we need to change to help community care workers or community?
Clinical Interventions in Aging

\section{Publish your work in this journal}

Clinical Interventions in Aging is an international, peer-reviewed journal focusing on evidence-based reports on the value or lack thereof of treatments intended to prevent or delay the onset of maladaptive correlates of aging in human beings. This journal is indexed on PubMed Central, MedLine,

\section{Dovepress}

CAS, Scopus and the Elsevier Bibliographic databases. The manuscript management system is completely online and includes a very quick and fair peer-review system, which is all easy to use. Visit http://www.dovepress. com/testimonials.php to read real quotes from published authors. 